\title{
ESTAQUIA E ALPORQUIA DE Tibouchina fothergillae (D.C.) Cogn. (MELASTOMATACEAE) COM A APLICAÇÃO DE ÁCIDO NAFTALENO ACÉTICO
}

\author{
STEM CUTTING AND AIR LAYERING OF Tibouchina fothergillae (D.C.) Cogn. \\ (MELASTOMATACEAE) WITH THE APPLICATION OF NAPHTHALENE ACETIC \\ ACID
}

\author{
Tatiana Mazon CÉZAR ${ }^{1}$ \\ Fernanda Castelhano de SOUZA ${ }^{1}$ \\ Raquel Thiana MACIEL ${ }^{1}$ \\ Waleska DEMBISKI ${ }^{1}$ \\ Katia Christina ZUFFELLATO-RIBAS ${ }^{2}$ \\ Luciana Lopes Fortes RIBAS ${ }^{3}$ \\ Henrique Soares KOEHLER ${ }^{4}$
}

\begin{abstract}
RESUMO
Tibouchina fothergillae é uma espécie nativa brasileira, com potencial ornamental e para recuperação de áreas degradadas. Entretanto, o tamanho reduzido de suas sementes e a dificuldade de coleta das mesmas requer metodologias específicas, fazendo com que a propagação sexuada da espécie não seja viável comercialmente. Objetivou-se neste trabalho estudar a propagação vegetativa de $T$. fothergillae, por estaquia e alporquia, com a aplicação de ácido naftaleno acético. $O$ material vegetal foi obtido de plantas matrizes localizadas no Campus III da UFPR, Curitiba-PR. Ambos experimentos foram instalados em agosto/2006, e avaliados aos 20 dias (estaquia) e 76 dias (alporquia). A aplicação de três diferentes concentrações $\left(0,500\right.$ e $\left.1000 \mathrm{mg} \mathrm{kg}^{-1}\right)$ de ácido naftaleno acético (ANA) foi feita em talco na base das estacas e em pasta de vaselina nos alporques. Houve $100 \%$ de enraizamento nas estacas. O número médio de raízes por estaca foi maior nos tratamentos com ANA (entre 20,88 e 21,88 ) que na testemunha $(10,58)$. Todavia, não houve diferença no comprimento médio das raízes por estaca, com média geral de $3,35 \mathrm{~cm}$. Na alporquia, o enraizamento variou entre 50 e $100 \%$. O tratamento com $1000 \mathrm{mg} \mathrm{kg}^{-1}$ de ANA promoveu maior número de raízes por alporque $(17,00)$ e maior comprimento médio das raízes por alporque $(11,73 \mathrm{~cm})$. Por estes resultados, considerou-se viável a propagação de $T$. fothergillae por estaquia ou alporquia. Recomenda-se o uso de ANA na concentração de $1000 \mathrm{mg} \mathrm{kg}^{-1}$ para aumentar o número de raízes em alporques, não sendo necessário na estaquia.
\end{abstract}

Palavras-chave: quaresmeira; propagação vegetativa; ANA; enraizamento; mergulhia aérea.

\begin{abstract}
Tibouchina fothergillae is a Brazilian native species with ornamental potential and adequate for ecosystems rehabilitation. However, the species has very small seeds, hard to collect by conventional methods, making large scale seed propagation not commercially feasible. The aim of this work was to propagate $T$. fothergillae by stem cuttings and air layering, with application of naphthalene acetic acid. Samples were obtained from plants located at the Campus III of the Federal University of Parana (UFPR), in Curitiba-PR-Brazil. Both experiments were installed in August, 2006 and evaluated after 20 days (stem cutting) or 76 days (air layering). The concentrations of 0,500 , and $1000 \mathrm{mg} \mathrm{kg}^{-1}$ of naphthalene acetic acid (NAA) were applied in powder in the cuttings and in vaseline paste in the layerings. It was observed $100 \%$ of rooting on stem cuttings. The averages of roots per cutting treated with NAA (20.88 and 21.88) were higher than the control's average (10.58). However, there weren't differences of the root length among treatments (grand mean $=3.35 \mathrm{~cm}$ ). On the air layering experiment, rooting varied from 50 to $100 \%$. The $1000 \mathrm{mg} \mathrm{kg}^{-1}$ NAA treatment promoted the largest number of roots per layering $(17.00)$ and higher root length mean $(11.73 \mathrm{~cm})$. Through these results, both techniques can be considered suitable for $T$. fothergillae's propagation. It's recommended to use NAA $\left(1000 \mathrm{mg} \mathrm{kg}^{-1}\right)$ to increase the number of roots on air layerings. NAA application isn't necessary for stem cuttings.
\end{abstract}

Key-words: "quaresmeira"; vegetative propagation; NAA; rooting; air layering.

\footnotetext{
${ }^{1}$ Bióloga, Universidade Federal do Paraná (UFPR), Curitiba, Paraná; Brasil. E-mail: tmcezar@hotmail.com, fercastelhano_bio@yahoo.com.br; raqmaciel@hotmail.com, waleskadembiski@hotmail.com.

${ }^{2}$ Bióloga, Dra., Professora Associada II, Departamento de Botânica, Setor de Ciências Biológicas, Universidade Federal do Paraná (UFPR), Centro Politécnico, Jardim das Américas, Caixa postal 19031, CEP: 81531-970, Curitiba, Paraná, Brasil. E-mail: kazu@ufpr.br. Autora para correspondência.

${ }^{3}$ Bióloga, Dra., Professora Associada I, Departamento de Botânica, Setor de Ciências Biológicas, Universidade Federal do Paraná (UFPR), Curitiba, Paraná, Brasil. E-mail: Ilfribas@ufpr.br

${ }^{4}$ Eng. Florestal, Dr., Professor Associado I, Departamento de Fitotecnia e Fitossanitarismo, Setor de Ciências Agrárias, Universidade Federal do Paraná (UFPR), Curitiba, Paraná, Brasil. E-mail: koehler@ufpr.br.
} 
CÉZAR, T.M. et al. Estaquia e alporquia de Tibouchina fothergillae...

\section{INTRODUÇÃO}

Plantas da família Melastomataceae estão distribuídas nas regiões tropicais e subtropicais do mundo e correspondem a cerca de 170 gêneros e aproximadamente 4.600 espécies. (Barroso et al., 1991; Joly, 1998). A família abriga o gênero Tibouchina, com cerca de 200 espécies, popularmente conhecidas como quaresmeiras (Barroso et al., 1991; Joly, 1998) as quais são plantas tipicamente pioneiras, rústicas e tolerantes à luminosidade direta, com potencial de uso em recuperação e reflorestamento de áreas degradadas, além de apresentarem características ornamentais, sendo muito utilizadas no paisagismo urbano (Andrade, 1995; Silva \& Affonso, 2005; Santos \& Santos, 2007). Tibouchina fothergillae é uma espécie de porte arbustivo, com cerca de 1,5 $\mathrm{m}$ de altura, folhas membranáceas e lanceoladas, e flores de coloração púrpura, podendo ser encontrada nos estados de Minas Gerais, Paraná, Rio de Janeiro e São Paulo, florescendo e frutificando em quase todos os meses do ano, sendo os mais representativos abril e maio (Silva \& Affonso, 2005).

Apesar da grande representatividade no banco de sementes de Floresta Atlântica Montana, as espécies de Melastomataceae apresentam grande número de sementes abortadas e baixa germinabilidade (Elisson et al., 1993; Barroso et al. 1999; Tabarelli \& Mantovani, 1999), fato que pode ser creditado à ausência de embriões na semente, como observado em Tibouchina granulosa (Zaia \& Takaki, 1998). Lorenzi (2002a, 2002b) relata baixas taxas de germinação para $T$. candolleana, $T$. granulosa e T. mutabilis.

O tamanho reduzido das sementes de Tibouchina, (milhões de unidades por quilograma) dificulta a coleta das mesmas, a qual é feita pela colheita das infrutescências diretamente da árvore, quando da abertura espontânea dos frutos, e é notada pela nuvem de minúsculas sementes formada quando se balança os ramos da planta (Lorenzi, 2002a, 2002b). Há também outros fatores que complicam a propagação sexuada de espécies florestais em viveiros, como a definição da época ideal da colheita das sementes, bem como do ponto de maturidade do fruto compatível com a maturidade da semente (Simão et al., 2007). Em virtude disto, a estaquia e a alporquia poderiam ser empregadas para a propagação vegetativa de $T$. fothergillae.

Baseadas na capacidade dos tecidos se regenerarem e emitirem raízes, a estaquia e a alporquia são técnicas comumente utilizadas na multiplicação vegetativa de várias espécies. A estaquia é um método mais facilmente conduzido e capaz de produzir maior número de mudas, enquanto que a principal vantagem da alporquia é a produção de mudas de maior porte, já adaptadas a condições ambientais externas (Hartmann et al. 2002). Independentemente da técnica, o enraizamento pode ser potencializado pela adição de auxinas sintéticas, que são efetivos indutores da formação de raízes adventícias, e permitem a melhoria da qualidade do sistema radicial (Larcher, 2000; Hartmann et al., 2002; Kerbauy, 2004).

O objetivo deste trabalho foi observar a viabilidade de uso das técnicas de estaquia e alporquia na propagação vegetativa de Tibouchina fothergillae (Melastomataceae), e o efeito da aplicação de diferentes concentrações da auxina ácido naftaleno acético no enraizamento de estacas e alporques da espécie.

\section{MATERIAL E MÉTODOS}

As duas técnicas foram realizadas utilizando ramos semilenhosos de três plantas adultas localizadas no Campus III da Universidade Federal do Paraná, localizado no Centro Politécnico, em Curitiba, PR, no dia 17 de agosto de 2006. Na estaquia, o experimento foi instalado seguindo um delineamento inteiramente casualizado, com três tratamentos com quatro repetições, cada qual com dez estacas por unidade experimental, totalizando 120 estacas. $\mathrm{Na}$ alporquia, o experimento foi instalado seguindo um delineamento de blocos ao acaso consistindo de três blocos (plantas matrizes), com três tratamentos cada, com dois alporques por unidade experimental em duas plantas e um alporque por unidade experimental em uma das plantas (devido ao pequeno porte da mesma), totalizando 15 alporques. As variâncias dos tratamentos foram testadas quanto à homogeneidade pelo teste de Bartlett. A comparação das médias dos tratamentos foi feita com o teste de Tukey a $5 \%$ de probabilidade. A análise estatística foi realizada com 0 auxílio do programa MSTAT-C ${ }^{\circledR}$ (MSU, 2006).

\section{Estaquia}

Estacas caulinares de Tibouchina fothergillae foram confeccionadas com $10 \mathrm{~cm}$ de comprimento, e um par de folhas opostas na porção apical, com as lâminas cortadas pela metade, a base cortada em bisel e o ápice cortado transversalmente acima da última gema lateral. A desinfestação das estacas foi realizada por imersão total das mesmas em solução de hipoclorito de sódio $(\mathrm{NaOCl})$ a $0,067 \mathrm{~mol} \mathrm{dm}^{-3}$ durante $10 \mathrm{~min}$, seguida de lavagem em água corrente por $5 \mathrm{~min}$. $\mathrm{Na}$ base das estacas foi aplicado ácido naftaleno acético (ANA), sob a forma de talco, nas concentrações de 0,500 e $1000 \mathrm{mg} \mathrm{kg}^{-1}$. Em seguida, elas foram plantadas em tubetes de 53 $\mathrm{cm}^{3}$ contendo vermiculita de granulometria média previamente umedecida como substrato, e mantidas em casa-de-vegetação Van der Hoeven ${ }^{\circledR}$, com temperatura e umidade controladas $\left(24 \pm 2{ }^{\circ} \mathrm{C} ; 90 \%\right.$ de umidade relativa), durante 20 dias. Após esse período, o enraizamento (estacas que apresentaram raízes de pelo menos $1 \mathrm{~mm}$ de comprimento), o número de raízes por estaca e o comprimento médio das três maiores raízes por estaca foram avaliados. 
CÉZAR, T.M. et al. Estaquia e alporquia de Tibouchina fothergillae...

\section{Alporquia}

Alporques de Tibouchina fothergillae foram confeccionados com anelamento completo, a uma distância de $60 \mathrm{~cm}$ do ápice de ramos selecionados com cerca de $1,5 \mathrm{~cm}$ de diâmetro, tendo cada anelamento $3 \mathrm{~cm}$ de largura. Na região anelada foram aplicadas as concentrações de 0,500 e 1000 $\mathrm{mg} \mathrm{kg}{ }^{-1}$ de ANA, veiculado em pasta de vaselina. Os alporques foram então recobertos com vermiculita de granulometria média previamente umedecida, envolvendo-se o substrato com filme de polietileno amarrado nas extremidades. A avaliação da porcentagem de alporques enraizados, número de raízes por alporque, comprimento médio de raízes por alporque e alporques com presença de calos (mas não enraizados) foi realizada após 76 dias. Os alporques ficaram expostos às condições ambientais, cujas variações de temperatura foram de 9 a $22{ }^{\circ} \mathrm{C}$, e de pluviosidade entre 75 e $130 \mathrm{~mm}$ (SIMEPAR, 2006; Tabela 1).

TABELA 1 - Temperaturas máximas e mínimas e precipitação mensal no período de agosto a outubro de 2006 , registradas pela estação meteorológica de Curitiba-PR e fornecidas pelo SIMEPAR (2006).

\begin{tabular}{cccc}
\hline Médias de temperatura e pluviosidade & Agosto/2006 & Setembro/2006 & Outubro/2006 \\
\hline Temperatura máxima $\left({ }^{\circ} \mathrm{C}\right)$ & 20 & 20 & 22 \\
Temperatura mínima $\left({ }^{\circ} \mathrm{C}\right)$ & 9 & 9 & 11 \\
Pluviosidade $(\mathrm{mm})$ & 75 & 110 & 130 \\
\hline
\end{tabular}

\section{RESULTADOS E DISCUSSÃO}

\section{Estaquia}

Após 20 dias da instalação do experimento, foi verificado enraizamento de $100 \%$ em todos os tratamentos (Tabela 2). A facilidade de formação de raízes em estacas de $T$. fothergillae já havia sido observada por Cavichiolo et al. (2005), que obtiveram sucesso de $97,5 \%$ a $100 \%$ e por Bortolini et al. (2005), que obteve $100 \%$ de indução radicial. O elevado enraizamento na testemunha indica que $T$. fothergillae não necessita do uso de reguladores vegetais, podendo ser considerada uma espécie de fácil enraizamento. Outras espécies ornamentais, como é o caso da azaléia, também não exigiram aplicação de ANA para enraizamento satisfatório (Carvalho et al., 2002). Além desta, espécies como o guaco (Mikania glomerata Spr.) (Colodi et al., 2008) e a caliandra (Calliandra selloi Spr. var. rosa) (Lima et al., 2006) também apresentaram mais de $90 \%$ de enraizamento em estacas sem o uso de reguladores vegetais.

TABELA 2 - Porcentagem de estacas enraizadas (EE), número médio de raízes por estaca (NRE) e comprimento médio das três maiores raízes por estaca (CMR) de $T$. fothergillae, com a utilização de concentrações de ácido naftaleno acético. Curitiba-PR, 2006.

\begin{tabular}{cccc}
\hline $\begin{array}{c}\text { Tratamentos } \\
\left(\mathrm{mg} \mathrm{kg}^{-1} \text { ANA }\right)\end{array}$ & EE $(\%)$ & NRE & CMR $(\mathrm{cm})$ \\
\hline 0 & $100,00 \mathrm{a}$ & $10,58 \mathrm{~b}$ & $2,87 \mathrm{a}$ \\
500 & $100,00 \mathrm{a}$ & $20,88 \mathrm{a}$ & $3,71 \mathrm{a}$ \\
1000 & $100,00 \mathrm{a}$ & $21,88 \mathrm{a}$ & $3,47 \mathrm{a}$ \\
\hline Média geral & 100,00 & 17,78 & 3,35 \\
C.V. $(\%)$ & 0,00 & 19,39 & 15,05 \\
\hline
\end{tabular}

* Médias seguidas pela mesma letra na coluna não diferem estatisticamente pelo teste de Tukey ao nível de $5 \%$ de probabilidade. $\mathrm{CV}=$ coeficiente de variação

A alta porcentagem de enraizamento observada, inclusive nas testemunhas, pode ser devida à presença de folhas nas estacas, uma vez que sua presença influencia o enraizamento, por serem fontes de auxinas, carboidratos e outras substâncias. (Hartmann et al., 2002). No entanto, nem todas as espécies do gênero Tibouchina apresentam facilidade de enraizamento em estacas. Knapik et al. (2003), estudando a propagação vegetativa via estaquia de $T$. pulchra, verificaram enraizamento entre $0,0 \%$ e $8,4 \%$ sem a aplicação de reguladores vegetais.
Quanto ao número de raízes por estaca de $T$. fothergillae, as médias dos tratamentos com 500 e $1000 \mathrm{mg} \mathrm{kg}^{-1}$ de ANA $(20,9$ e $21,9 \mathrm{~cm}$, respectivamente) foram significativamente superiores à da testemunha $(10,6 \mathrm{~cm})$. Entre os tratamentos de 500 e $1000 \mathrm{mg} \mathrm{kg}^{-1}$, não houve diferença significativa entre as médias (Tabela 2). Já quanto ao comprimento médio das três maiores raízes por estaca de $T$. fothergillae, não foi observada diferença significativa dentre os três tratamentos. O comprimento variou entre 2,9 e 3,7 $\mathrm{cm}$, sendo a maior média obtida no tratamento com 
CÉZAR, T.M. et al. Estaquia e alporquia de Tibouchina fothergillae...

$500 \mathrm{mg} \mathrm{kg}^{-1}$ de ANA (Tabela 2). Os dados obtidos demonstraram que a utilização do regulador não influenciou o enraizamento e o comprimento de raízes, porém incrementou o número de raízes por estaca. Respostas semelhantes foram obtidas com o guaco por Colodi et al. (2008), com número médio de raízes por estaca significativamente maior nos tratamentos com ANA do que na testemunha e comprimento médio de raízes sem diferença estatística com e sem o uso do regulador, e pode ser um indício de que a auxina exógena promoveu um direcionamento de reservas mais para a produção de novas raízes adventícias do que para o alongamento das mesmas (Colodi et al., 2008). Já para Caliandra tweediei e C. selloi, a aplicação de ANA não implicou em diferença no enraizamento, número médio de raízes por estaca e comprimento médio de raízes (Lima et al., 2006), evidenciando que o regulador apresenta ações diversas em diferentes espécies.

Uma vez que o enraizamento de estacas de $T$. fothergillae foi de $100 \%$, as variáveis mortalidade e sobrevivência não existiram. Também não foram encontradas estacas de $T$. fothergillae com a formação de calos.

\section{Alporquia}

$\mathrm{Na}$ alporquia de $T$. fothergillae, houve formação de calos de coloração esbranquiçada e consistência compacta. Não existe uma ligação direta entre a formação de calos e o enraizamento, porém ambas as respostas possuem uma dependência de fatores internos similares e de condições ambientais favoráveis (Zuffellato-Ribas \& Rodrigues, 2001). A ocorrência de calos foi verificada em $100 \%$ dos alporques, enraizados ou não, o que sugere que não houve influência do ácido naftaleno acético na formação de calos, provavelmente sendo esta devida apenas ao anelamento. $\mathrm{O}$ anelamento de ramos produz uma maior concentração de carboidratos na região, o que pode auxiliar tanto a formação de calos quanto a formação de raízes adventícias (Araújo et al., 2004). Em outras espécies, como o marmeleiro japonês (Chaenomelis sinensis L.), Pio et al. (2007) obtiveram porcentagens de 96,7 a $100 \%$ de alporques com calos sem o uso de reguladores, em diferentes épocas do ano.

Com relação ao enraizamento dos alporques de $T$. fothergillae, houve variação de 50 a $100 \%$, com média geral de $72,22 \%$, não havendo diferença estatística entre os tratamentos, sendo a maior porcentagem observada no tratamento com $1000 \mathrm{mg} \mathrm{kg}^{-1}$ de ANA (Tabela 3). Apesar de não haver diferença estatística entre os tratamentos, pode-se dizer que o uso de regulador vegetal otimizou o enraizamento dos alporques, conforme foi observado para videira muscadínea (Vitis rotundifoli Michx.) (Pacheco et al., 1998), pessegueiro (Prunus persica (L.) Batsch) (Castro \& Silveira, 2003) e jabuticabeira (Plinia trunciflora (DC.) Berg) (Danner et al., 2006) e aroeira (Schinus terebintifolius Raddi) (Gonçalves et al., 2007).

TABELA 3 - Porcentagem de alporques enraizados ( $A E$ ), número médio de raízes por alporque (NRA), comprimento médio das três maiores raízes por alporque (CMR) e alporques com formação de calos (AC) de $T$. fothergillae, com a utilização de concentrações de ácido naftaleno acético. Curitiba-PR, 2006.

\begin{tabular}{ccccc}
\hline $\begin{array}{c}\text { Tratamentos } \\
\left(\mathrm{mg} \mathrm{kg}^{-1} \mathrm{ANA}\right)\end{array}$ & $\mathrm{AE}(\%)$ & NRA & CMR $(\mathrm{cm})$ & AC (\%) \\
\hline 0 & $50,00 \mathrm{a}$ & $1,50 \mathrm{~b}$ & $1,70 \quad \mathrm{~b}$ & $50,00 \mathrm{a}$ \\
500 & $66,67 \mathrm{a}$ & $2,83 \mathrm{~b}$ & $2,85 \quad \mathrm{~b}$ & $33,33 \mathrm{a}$ \\
1000 & $100,00 \mathrm{a}$ & $17,00 \mathrm{a}$ & $11,73 \mathrm{a}$ & $0,00 \mathrm{a}$ \\
\hline Média geral & 72,22 & 7,11 & 5,43 & 27,78 \\
C.V. (\%) & 46,15 & 32,05 & 14,72 & 120,00 \\
\hline
\end{tabular}

* Médias seguidas pela mesma letra na coluna não diferem estatisticamente pelo teste de Tukey ao nível de $5 \%$ de probabilidade. $\mathrm{CV}=$ coeficiente de variação

Em estudo com alporquia de $T$. fothergillae, Fanti et al. (2005) observaram a ocorrência de enraizamento dos alporques de apenas com o anelamento, sendo mais um indicativo da facilidade de enraizamento da espécie. O anelamento do ramo pode estimular o desenvolvimento de raízes em alporques, por provocar a retenção de substâncias promotoras do enraizamento produzidas pelas folhas e gemas, como hormônios e carboidratos, dentre outros (Hartmann et al., 2002). Outras espécies que apresentaram enraizamento apenas com o anelamento do alporque foram a espirradeira
(Nerium oleander L.) (Marçallo et al., 2001) e o pessegueiro (Castro \& Silveira, 2003). Ao contrário do observado para Ginkgo biloba (Bitencourt et al., 2007) no qual somente o anelamento não foi suficiente para a formação de raízes adventícias, sendo necessária a adição de auxinas sintéticas para otimizar o processo. Para aroeira (Schinus terebinthifolius Raddi), Gonçalves et al. (2007) evidenciaram a importância do uso de reguladores vegetais no enraizamento em matrizes adultas, uma vez que houve resposta diretamente proporcional à dosagem de auxina exógena.

$\mathrm{O}$ número de raízes por alporque de $T$. 
fothergillae foi significativamente superior no tratamento com $1000 \mathrm{mg} \mathrm{kg}$ de ANA, apresentando em média 17,00 raízes, enquanto os demais tratamentos apresentaram médias de 1,50 e 2,83 raízes por alporque (Tabela 3 ). Este resultado é importante, visto que uma maior quantidade de raízes é um fator que influencia diretamente 0 sucesso do plantio das mudas a campo, incrementando sensivelmente a taxa de pegamento das plantas (Smarsi et al., 2008).

O melhor resultado para o comprimento médio das três maiores raízes por alporque de $T$. fothergillae $(11,73 \mathrm{~cm})$ foi obtido no tratamento com $1000 \mathrm{mg} \mathrm{kg}^{-1}$ de ANA. A testemunha e o tratamento com $500 \mathrm{mg} \mathrm{kg}^{-1}$ apresentaram, respectivamente, $1,70 \mathrm{~cm}$ e 2,85 cm de comprimento médio (Tabela 3). A variável comprimento médio das três maiores raízes, portanto, foi a única que apresentou diferença entre tratamento e testemunha nos experimentos de alporquia e estaquia. Bem como um maior número de raízes, raízes de maior comprimento, mais vigorosas, também influenciam o sucesso do desenvolvimento das mudas a campo (Hartmann et al., 2002).

\section{CONCLUSÕES}

Nas condições em que foi realizado o presente experimento, pode-se concluir que $T$. fothergillae é uma espécie de fácil enraizamento, e sua propagação é viável tanto pela estaquia quanto pela alporquia.

O uso de ANA não é necessário para o enraizamento de estacas caulinares, porém sua utilização incrementa significativamente o número de raízes formadas e, no caso da alporquia, também o comprimento médio das raízes, sendo recomendada, neste caso, a aplicação de $1000 \mathrm{mg}$ $\mathrm{kg}^{1}$ ANA.

\section{AGRADECIMENTOS}

À mestre Bárbara Guerreira Alpande Ferreira e à doutoranda Juliany de Bitencourt, pelo auxílio na instalação dos experimentos e interpretação dos resultados. Ao Departamento de Botânica da UFPR, pela estrutura física e equipamentos.

\section{REFERÊNCIAS}

1. ANDRADE, A. C. S. Efeito da luz e da temperatura na germinação de Leandra breviflora COGN., Tibouchina benthamiana Cogn., Tibouchina grandifolia Cogn. e Tibouchina moricandiana (DC.) Baill. (Melastomataceae). Revista Brasileira de Sementes, v. 17, n. 1, p. 29-35, 1995.

2. ARAÚJO, J. P. C.; SCARPARE FILHO, J. A.; RODRIGUES, A. Alporquia em Lichia: épocas e concentrações de carboidratos solúveis em ramos. In: CONGRESSO BRASILEIRO DE FRUTICULTURA, 18., 2004, Florianópolis. Anais... Florianópolis: Adaltech, 2004. CD- ROM.

3. BARROSO, G. M. et al. Sistemática de angiospermas do Brasil. Viçosa: Universidade Federal de Viçosa - Imprensa Universitária, 1991, v. 2. 377 p.

4. BARROSO, G. M. et al. Frutos e sementes: morfologia aplicada à sistemática de dicotiledôneas. Viçosa: Universidade Federal de Viçosa - Imprensa Universitária, 1999. $443 \mathrm{p}$.

5. BITENCOURT, J. et al. Propagação vegetativa de Ginkgo biloba por alporquia. Revista Brasileira de Plantas Medicinais, v. 9, n. 2, p. 71-74, 2007.

6. BORTOLINI, M. et al. Enraizamento de quatro espécies do gênero Tibouchina Aubl. (Melastomataceae Juss.). In: CONGRESSO NACIONAL DE BOTÂNICA, 56., 2005, Curitiba. Resumos... Curitiba: Digittal Solutions, 2005. CD-ROM.

7. CARVALHO, D. B.; SILVA, L. M.; ZUFFELLATO-RIBAS, K. C. Indução de raízes em estacas semilenhosas de azaléia através da aplicação de ácido naftaleno-acético em solução. Scientia Agraria, v. 3, n. 1-2, p. 97-101, 2002.

8. CASTRO, L. A. S.; SILVEIRA, C. A. P. Propagação vegetativa do pessegueiro por alporquia. Revista Brasileira de Fruticultura, v. 25, n. 2, p. 368-370, 2003.

9. CAVICHIOLO, L. E. et al. Propagação vegetativa por estaquia de Tibouchina fothergillae Cogn. e Tibouchina sp (Melastomataceae). In: CONGRESSO NACIONAL DE BOTÂNICA, 56., 2005, Curitiba. Resumos... Curitiba: Digittal Solutions, 2005. CD-ROM.

10. COLODI, F. G. et al. Propagação vegetativa de guaco com adição de ácido naftalenoacético. Scientia Agraria, v. 9, n. 1, p. $95-98,2008$.

11. DANNER, M. A. et al. Enraizamento de jaboticabeira (Plinia trunciflora) por mergulhia aérea. Revista Brasileira de Fruticultura, v. 28, n. 3, p. 530-532. 2006.

12. ELISSON, A. M. et al. Seed and seedling ecology of neotropical Melastomataceae. Ecology, v. 74, n. 6, p. 1733-1749, 1993.

13. FANTI, F. et al. Alporquia de Tibouchina fothergillae utilizando diferentes concentrações de ácido indol butírico (IBA). In: CONGRESSO NACIONAL DE BOTÂNICA, 56., 2005, Curitiba. Resumos... Curitiba: Digittal Solutions, 2005. CD-ROM.

14. HARTMANN, H. T. et al. Plant Propagation: principles and practices. 7. ed. New York: Prentice Hall, 2002. 880 p.

15. GONÇALVES, M. P. M. et al. Propagação vegetativa da aroeira (Schinus terebintifolius) por alporquia. Revista Brasileira de Biociências, v. 5, n. supl. 2, p. 363-365, 2007.

16. JOLY, A. B. Botânica: Introdução à taxonomia vegetal. 12. ed.São Paulo: Nacional, 1998. 777 p.

17. KERBAUY, G. B. Fisiologia vegetal. Rio de Janeiro: Guanabara Koogan, 2004. 452 p.

18. KNAPIK, J. G. et al. Influência da época de coleta e da aplicação de ácido indol butírico na propagação por estaquia da Tibouchina pulcra (Cham.) Cogn. (quaresmeira). Iheringia: Série Botânica, v. 58, n. 2, p. 171-179, 2003.

19. LARCHER, W. Ecofisiologia vegetal. São Carlos: RIMA, 2000. 531 p.

20. LIMA, D. M. et al. Substratos e concentrações de ácido naftaleno acético no enraizamento de estacas semilenhosas de Calliandra selloi e Calliandra tweediei. Scientia Agraria, v. 7, n. 1-2, p. 105-111, 2006.

21. LORENZI, H. Árvores brasileiras: manual de identificação e cultivo de plantas arbóreas nativas do Brasil. 4. ed. Nova Odessa: Instituto Planturum, 2002a, 384 p, v. 1. 
CÉZAR, T.M. et al. Estaquia e alporquia de Tibouchina fothergillae...

22. LORENZI, H. Árvores brasileiras: manual de identificação e cultivo de plantas arbóreas nativas do Brasil. 4. ed. Nova Odessa: Instituto Planturum, 2002b, 384 p, v. 2.

23. MARÇALLO, F. A.; ALMEIDA, R. C.; ZUFFELLATO-RIBAS, K. C. Propagação da espirradeira por meio da técnica da alporquia em diferentes substratos. Scientia Agraria, v. 2, n. 1-2, p. 123-125, 2001.

24. MICHIGAN STATE UNIVERSITY (MSU). MSTAT-C ${ }^{\circledR}$ - Desing, management and statistical research tool, versão 2.10. Disponível em: <http://www.msu.edu/ freed/mstatc.htm>. Acesso: set 2006.

25. PACHECO, A. C.; CASTRO, P. R. C.; APPEZATO-DA-GLÓRIA, B. Aspectos anatômicos do enraizamento da videira muscadínia (Vitis rotundifolia Michx.) através de alporquia. Scientia Agricola, v. 55, n. 2, p. 210-217, 1998.

26. PIO, R. et al. Propagação do marmeleiro 'japonês' por estaquia e alporquia realizadas em diferentes épocas. Ciência e Agrotecnologia, v. 31, n. 2, p. 570-574, 2007.

27. SANTOS, S. R. G.; SANTOS, D. C. Estudo de maturação de uma espécie de restinga, Tibouchina pulchra (manacá-dapraia). Instituto Florestal. Série Registros, n. 31, p. 191-195, 2007.

28. SILVA, C. V.; AFFONSO, P. Levantamento de Tibouchina AUBL. (Melastomataceae) no parque estadual da serra do mar - núcleo Curucutu - São Paulo. Revista do Instituto Florestal, v. 17, n. 2, p. 195-206, 2005.

29. SIMÃO, E.; NAKAMURA, A.T.; TAKAKI, M. Época de colheita e capacidade germinativa de sementes de Tibouchina mutabilis (Vell.) Cogn. (Melastomataceae). Biota Neotropica, v. 7, n. 1, p. 67-73, 2007.

30. SMARSI, R.C. et al. Concentrações de ácido indolbutírico e tipos de substrato na propagação vegetativa de lichia Revista Brasileira de Fruticultura, v. 30, n. 1, p. 07-11, 2008.

31. SISTEMA METEOROLÓGICO DO PARANÁ (SIMEPAR) - Instituto Tecnológico. 2006. Disponível em: $<$ www.simepar.br>. Acesso: nov. 2006.

32. TABARELLI, M.; MANTOVANI, W. A riqueza da floresta atlântica de encosta no Estado de São Paulo (Brasil). Revista Brasileira de Botânica, v. 22, n. 2, p. 217-223, 1999.

33. ZAIA, J. E.; TAKAKI, M. Estudo da germinação de sementes de espécies arbóreas pioneiras: Tibouchina pulcra Cogn e Tibouchina granulosa Cogn.(Melastomataceae) Acta Botanica Brasilica, v. 12, n. 3, p. 221-229, 1998.

34. ZUFFELLATO-RIBAS, K. C.; RODRIGUES, J. D. Estaquia: Uma abordagem dos principais aspectos fisiológicos. Curitiba: [K. C. Zuffellato-Ribas], 2001. 39 p.

Recebido em 09/03/2009

Aceito em 29/07/2009 